\title{
NEUROPHENOMENOLOGY AND CONTEMPLATIVE EXPERIENCE
}

\author{
EVAN THOMPSON
}

\section{INTRODUCTION}

Scientific investigation of the mind, known since the 1970s as 'cognitive science', is an interdisciplinary field of research comprising psychology, neuroscience, linguistics, computer science, artificial intelligence, and philosophy of mind. The presence of philosophy in this list is telling. Cognitive science, although institutionally well established, is not a theoretically settled field like molecular biology or high-energy physics. Rather, it includes a variety of competing research programmes-the computational theory of mind (also known as classical cognitive science), connectionism, and dynamical and embodied approaches-whose underlying conceptions of mentality and its relation to biology, on the one hand, and to culture, on the other, are often strikingly different (see Clark 2001, for a useful overview).

It is important to keep this situation in mind in any discussion of the relationship between cognitive science and religion, for different theoretical perspectives in cognitive science can combine with different scientific approaches to religion. Rather than review these possibilities here, however, I shall describe one recent approach, known as neurophenomenology (Lutz and Thompson 2003; Varela 1996). Although neurophenomenology is not directly concerned with the cognitive science of religion, it is highly relevant to this field, especially the psychology and biology of religious experience.

Neurophenomenology is an offshoot of the embodied approach in cognitive science (Varela et al. 1991). The central idea of the embodied approach is that 
cognition is the exercise of skilful know-how in situated action. The most important feature of this approach, for our purposes here, is that experience is not seen as an epiphenomenal side issue, but is considered central to any adequate understanding of the mind, and accordingly needs to be investigated in a careful phenomenological manner. Phenomenology and experimental cognitive science are thus seen as complementary and mutually informing modes of investigation. Neurophenomenology builds on this view with the specific aim of understanding the nature of consciousness and subjectivity and their relation to the brain and body.

The working hypothesis of neurophenomenology is that phenomenological accounts of the structure of human experience and scientific accounts of cognitive processes can be mutually informative and enriching (Thompson 2006; Varela et al. 1991; Varela 1996). The term 'phenomenology' in this context refers to disciplined, first-person ways of investigating and analysing experience, as exemplified by the Western philosophical tradition of phenomenology (Moran 2000) and Asian contemplative philosophies, especially (though not exclusively) Buddhism. The reason why the Buddhist tradition is particularly relevant in this context is that its cornerstone is contemplative mental training and critical phenomenological and philosophical analysis of the mind based on such training (Dreyfus and Thompson, 2007; Lutz et al. 2007). Thus, neurophenomenology intersects with religion not so much as an object of scientific study, as it is for the cognitive science of religious beliefs and behaviours (e.g. Boyer 2001, 2003, 2005), but rather as a repository of contemplative and phenomenological expertise. According to neurophenomenology, such expertise could play an active and creative role in the scientific investigation of consciousness (Lutz et al., in press; Lutz and Thompson 2003; Thompson 2005).

Religion includes many other things besides contemplative experience, and many religions have little or no place for contemplative experience. Conversely, contemplative experience is found in other contexts besides religion, such as philosophy (McGee 2000). For these reasons, the term 'religion', at least as it is generally used in the West, is not a good designation for the kind of practice and experience that neurophenomenology seeks to bring into constructive engagement with cognitive science. A better description might be the kind of self-cultivation and self-knowledge cultivated by the world's contemplative 'wisdom traditions' (Depraz et al. 2003). Nor does the term 'science-religion dialogue' describe the motivation for neurophenomenology, for the aim is not to compare, evaluate, or adjudicate between the claims of science and religion, but to gain a deeper understanding of human experience by making contemplative phenomenology a partner in the scientific investigation of consciousness.

Of course, if 'science-religion dialogue' were understood as this sort of task-and many, especially in the Asian traditions, do understand it in this way-then the gap between neurophenomenology and religion-science discussions would not be so great. Similarly, if the goal of gaining a deeper understanding of human experience is taken as a religious practice-as it certainly is in Buddhism-then neurophenomenology might be seen as part of, or at least parallel to, religious practice. 


\section{The JAMESIAN HeRITAge}

Over 100 years ago, William James, in his Principles of Psychology, wrote that in the study of subjective mental phenomena, 'Introspective Observation is what we have to rely on first and foremost and always' (James 1981: 185). Psychology, as James presented it in this landmark book, is the study of subjective mental phenomenamental events as experienced in the first person-as well as the study of how mental states are related to their objects, to brain states, and to the environment. Whereas physiological psychology studies the relation of mind and brain, including the naturally evolved 'mutual fit' of mental faculties and the environment, introspection studies mental states in their subjective manifestations. Yet, what exactly is introspection? James continued: 'The word introspection need hardly be defined-it means, of course, the looking into our own minds and reporting what we there discover. Everyone agrees that we there discover states of consciousness' (James 1981: 185).

This passage is often quoted, but less often remarked is that James hardly thought introspection to be easy or an infallible guide to subjective mental life. Later in his book, when discussing sensed moments of transition in the subjective stream of thought and feeling, he wrote:

Let anyone try to cut a thought across in the middle and get a look at its section, and he will see how difficult the introspective observation of the transitive tracts is.... The attempt at introspective analysis in these cases is in fact like seizing a spinning top to catch its motion, or trying to turn up the gas quickly enough to see how the darkness looks (James 1981: 236-7)

James clearly did not think that we already know the nature and full range of thought and feeling simply because we are able to look into our own minds. In 1904 James heard the Theravada Buddhist renunciate Anagarika Dharmapala lecture at Harvard on the Buddhist conception of mind. According to the Buddhist view, there is no single, permanent, enduring self underlying the stream of mental and physical events. Afterwards, James rose and proclaimed to the audience, 'This is the psychology everybody will be studying twenty-five years from now.' He apparently meant not so much Buddhist psychology per se, but a psychology of the full developmental range of human consciousness, pursued with the kind of phenomenological precision exemplified by Buddhism (Taylor 1996: 146).

James's prediction, of course, was too optimistic. The words of another founding father of American psychology, James McKeen Cattell, also from 1904, indicate the path that much of psychology took in the years to come: 'It is usually no more necessary for the subject in a psychology experiment to be a psychologist than it is for the vivisected frog to be a physiologist' (Cattell 1904, as quoted by Lyons 1986: 23). The strategy that psychology pursued was to objectify the mind as much as possible, either as behavioural performance, physiological response, or, with the rise of cybernetics and then cognitive science, as non-conscious information processing. 'Consciousness' became a taboo term; introspection was rejected as a method for investigating the mind; and it was no longer necessary for the psychologist to have 
any disciplined first-person expertise in the subjectivity of mental life. Although there were notable exceptions to this trend, such as Gestalt psychology and phenomenological psychology, this 'taboo of subjectivity' (Wallace 2000) has influenced the scientific study of the mind for decades.

It has taken over a century, not a quarter of one, for the science of mind to begin to find its way back to James's vision of a science of mental life, including 'the varieties of religious experience' (James 1997), which integrates experimental psychology, neuroscience, and phenomenology. In recent years, a small but growing number of cognitive scientists have come to accept that there cannot be a complete science of the mind without understanding subjectivity and consciousness, and that cognitive science accordingly needs to make systematic use of introspective first-person reports about subjective experience (Jack and Roepstorff 2002, 2003). As cognitive neuroscientist Chris Frith recently stated: 'A major programme for 21st century science will be to discover how an experience can be translated into a report, thus enabling our experiences to be shared' (Frith 2002: 374).

\section{Contemplative Mental Training and Cognitive Science}

This renewed appreciation of the first-person perspective raises the question of how to obtain precise and detailed first-person accounts of experience. On the one hand, it stands to reason that people vary in their abilities as observers and reporters of their own mental lives, and that these abilities can be enhanced through mental training of attention, emotion, and metacognition. Contemplative practice is a vehicle for precisely this sort of cognitive and emotional training. On the other hand, it stands to reason that mental training should be reflected in changes to brain structure, function, and dynamics. Hence, contemplative practice could become a research tool for developing better phenomenologies of subjective experience and for investigating the neural correlates of consciousness.

The potential importance of contemplative mental training for scientific research on consciousness is central to neurophenomenology (Lutz et al. 2007). Concretely, neurophenomenology proposes to incorporate 'first-person methods' of examining experience into experimental research on subjectivity and consciousness. Firstperson methods sensitize individuals to their own mental lives through the systematic training of attention, emotion regulation, and metacognitive awareness (awareness of cognition) (Varela and Shear 1999). Such methods and training have been central to the Buddhist tradition since its inception (Wallace 1998, 1999). In Tibetan Buddhism, contemplative mental training is often described as a systematic process of 'familiarizing oneself' with the moment-to-moment character of mental events 
(Lutz, Dunne, and Davidson, in press). This description points towards the relevance of contemplative mental training to neurophenomenology: contemplative training cultivates a capacity for sustained, attentive awareness of the moment-to-moment flux of experience, or what James famously called 'the stream of consciousness'. For this reason, the Buddhist tradition holds special interest for neurophenomenology (Lutz et al. 2007; Varela et al. 1991).

It is worth reconsidering, from this vantage-point of contemplative mental training, how psychology came to reject introspection shortly after James. According to the standard history, introspection was given a fair try but failed. It allegedly failed because the two rival schools of introspectionist psychology were unable to agree whether there was such a thing as imageless thought. James had already observed, however, that the form of introspection practised by these schools was stilted and tedious, because it focused on the sensations caused by impoverished sensory stimuli (James 1981: 191-2). It is not surprising that introspection of this sort turned out to be so unilluminating, as Gestalt psychologists and phenomenologists also later remarked (Köhler 1947: 67-99; Merleau-Ponty 1962: 3-12). Furthermore, the textbook history neglects to mention that the rival schools did agree with each other at the descriptive level of introspective phenomenology; their disagreement was instead at the level of theoretical or causal interpretation. One lesson to be learned from this debate, therefore, is not that introspection is a useless method for obtaining descriptive accounts of subjective experience, but rather that psychology needs to discriminate carefully between the description of subjective phenomena and causalexplanatory theorizing (Hurlbert and Heavey 2001). A similar lesson should be drawn from the famous studies of Nisbett and Wilson in 1977: they observed that subjects often said that their behaviour was caused by mental events when it was really the result of external manipulation. Yet these inaccurate subjective reports were causal-explanatory in form, not rigorously descriptive and phenomenological. Again the lesson to be learned is that experimental participants need to be coached to pay strict attention to their felt cognitive processes and to avoid causal-explanatory conjectures (Hurlbert and Heavey 2001).

Yet how is such attention to be cultivated? First-person methods of examining experience are concerned with precisely this question (Varela and Shear 1999). What makes Buddhist contemplative mental discipline exemplary in this context is its pragmatic refinement and theoretical sophistication (Depraz et al. 2003). Whereas James described introspection as simply 'looking into our own minds and reporting what we there discover', Buddhism speaks of sustained attention to, and analytic discernment of, one's own mental processes. Buddhist phenomenology distinguishes between attentional stability and instability due to mental excitation, and between attentional vividness and dullness due to mental laxity (Wallace 1999). Buddhist phenomenology also discusses the metacognitive monitoring of these qualities of attention, and Buddhist epistemology discusses the degree to which a mental cognition ascertains or fails to ascertain its mental object, according to various conditions (Dreyfus 1997). According to this perspective, if the stream of thought and feeling is 
lucid, rather than turbulent and murky, then introspection in James's sense will be much richer in its discoveries and reports.

The working hypothesis of neurophenomenology appeals to this notion of refined first-person observation and description of subjective mental events. In an experimental context, this working hypothesis is twofold. First, phenomenologically precise first-person reports produced through mental training can provide important information about endogenous and externally uncontrollable fluctuations of moment-to-moment experience, such as quality of attention (Lutz et al. 2002). In addition, individuals who can generate and sustain a particular type of contemplative state cultivated in the Buddhist tradition-a state in which one's mind reposes, awake and alert, in the sheer 'luminosity' of consciousness (its quality of nonreflective and open awareness), without attending exclusively to any particular object or content-could provide important information about subjective aspects of consciousness not readily apparent or accessible to ordinary introspection or reflection (Lutz et al. 2007).

Second, the refined first-person reports produced through mental training can help to detect and interpret physiological processes relevant to consciousness, such as large-scale dynamical patterns of synchronous oscillatory activity in neural assemblies. Experimental studies following this approach have already cast light on the neurodynamics of conscious visual perception (Cosmelli et al. 2004; Lutz et al. 2002), epileptic activity and associated subjective mental events (Le Van Quyen and Petitmengin 2002), pain experience (Price et al. 2002; Rainville 2005), and the neurodynamical correlates of meditative states in highly trained Tibetan Buddhist practitioners (Lutz et al. 2004).

A further conjecture regarding contemplative mental training and experience is also important. Individuals who can generate and sustain specific sorts of mental states, and report on those states with a high degree of phenomenological precision, could provide a route into studying the causal efficacy of mental processes-how mental processes may modify the structure and dynamics of the brain and body. According to a neurodynamical perspective, mental states are embodied in largescale dynamical patterns of brain activity (Thompson and Varela 2001), and these patterns both emerge from distributed, local activities and also globally shape or constrain those local activities. One can thus conjecture that in intentionally generating a mental state, large-scale brain activity shifts from one coherent global pattern to another, and thereby entrains local neural processes (Freeman 1999; Thompson and Varela 2001). Thus, individuals who can intentionally generate, sustain, and report on distinct types of mental states could provide a way of testing and developing this idea.

Neurophenomenological research based on the foregoing hypotheses has potentially profound implications for both cognitive science and contemplative wisdom traditions. Were such research to prove fruitful, adept contemplatives could become a new kind of scientific collaborator, rather than simply a new type of experimental participant, for their first-person expertise would be directly mobilized within 
scientific research on the mind. To conclude this chapter, I would like to relate this idea to the overall theme of this Handbook.

\section{Towards a Contemplative Science OF MIND}

At the outset of this chapter, I stated that the aim of neurophenomenology is not to adjudicate between the claims of science and religion with regard to human experience, but to gain a deeper understanding of experience by making contemplative phenomenology a partner in the scientific investigation of consciousness. Varela, Thompson, and Rosch (1991) have described this approach as one of 'mutual circulation' between science and experience. According to the logic of mutual circulation, each domain of cognitive science, phenomenological philosophy, and contemplative mental training is distinct and has its own degree of autonomy-its own proper methods, motivations, and concerns-but they also overlap and share common areas. Thus, instead of being juxtaposed, either in opposition or as separate but equal, these domains can flow into and out of each other, and so be mutually enlightening.

This vision of mutual circulation does not fit easily within the established frameworks of the science-religion dialogue. We can appreciate this point by distinguishing the mutual circulation perspective from some of the main representative positions staked out in the science-religion dialogue, particularly as this dialogue touches on the nature of the human mind.

First, exploring the mutual circulation of mind science and contemplative experience is different from viewing science and religion as 'non-overlapping magisteria' (Gould 1999). This separate-but-equal strategy of insulating science and religion is highly problematic. It divides science and religion along the lines of a subject-object dualism: science addresses the empirical world conceived as a realm of objectivity, whereas religion address the subjective realm of human purposes, meaning, and value. Yet this subject-object dualism breaks down in the face of the intersubjectivity of human experience (Thompson 2005). Intersubjective experience is the common terrain of both science and religion, and it is poorly understood when fractured along the lines of a subject-object (or fact-value) dichotomy (Wallace 2005).

Second, the mutual circulation approach is different from looking for the physiological correlates of religious experiences (e.g. Newberg et al. 2001). The key difference is that adept contemplatives, as mentioned above, are considered not simply as experimental participants, but as scientific collaborators. Thus, the mutual circulation approach enables us to envision future cognitive scientists being schooled in contemplative mental training and phenomenology, as well as brain-imaging techniques and mathematical modelling, and future contemplative practitioners being 
knowledgeable in neuroscience and experimental psychology. Science and contemplative knowledge could thus mutually constrain and enrich each other. James envisioned this sort of prospect over a century ago in his writings on scientific psychology and religious experience (see Taylor 1996).

Third, the mutual circulation approach is different from the cognitive science of religion, especially evolutionary psychology explanations of religious thought and behaviour (Boyer 2001, 2003, 2005). Although these explanations are illuminating in linking religious concepts to our intuitive understandings of agency, social relations, and misfortune (see Boyer 2005), they neglect the contemplative aspect of certain religious traditions. Whereas evolutionary psychology takes religious notions and norms as objects of explanation for evolutionary and functionalist cognitive science, neurophenomenology looks to the role that contemplative mental training and experience can play in a phenomenologically enriched cognitive science.

A common feature of the three approaches to science and religion I have contrasted with the mutual circulation approach is that they take the concepts of 'science' and 'religion' largely for granted. These concepts, however, are deeply problematic. They are European intellectual categories that have been shaped in recent Western history by the science-religion conflicts of the European Enlightenment and modernity. As such, they do not map in any clear way on to the knowledge formations and social practices of certain other cultural traditions, in particular those of Asian contemplative wisdom traditions (see Hut 2003). As Wallace has recently written in his introduction to a volume on Buddhism and science:

The assertion that Buddhism includes scientific elements by no means overlooks or dismisses the many explicitly religious elements within this tradition.... Buddhism is very much concerned with human purposes, meaning, and value. But, like science, it is also concerned with understanding the realms of sensory and mental experience, and it addresses the questions of what the universe, including both objective and subjective phenomena, is composed of and how it works... Buddhism does address questions concerning the meaning and purpose of life, our ultimate origins and destiny, and the experiences of our inner life. But the mere fact that Buddhism includes elements of religion is not sufficient for singularly categorizing it as a religion, any more than it can be classified on the whole as a science. To study this discipline objectively requires our loosening the grip on familiar conceptual categories and preparing to confront something radically unfamiliar that may challenge our deepest assumptions. In the process we may review the status of science itself, in relation to the metaphysical axioms on which it is based. (Wallace 2003a: 9-10)

In this chapter, I have proposed that certain contemplative wisdom traditionsBuddhism most notably, though not exclusively-and certain approaches in cognitive science-the embodied approach and neurophenomenology-are not simply compatible, but mutually informative and enlightening. Through back-and-forth circulation, each approach can reshape the other, leading to new conceptual and practical understandings for both. At stake in this possibility is nothing less than the prospect of a mature science of the mind that can begin to do justice to the rich and diverse traditions of human contemplative experience. 


\section{References and Suggested Reading}

Boyer, P. (2001). Religion Explained: The Evolutionary Origins of Religious Thought. New York: Basic Books.

- (2003). 'Religious Thought and Behaviour as By-products of Brain Function', Trends in Cognitive Sciences, 3: 119-24.

- (2005). 'Gods, Spirits, and the Mental Instincts that Create Them', in J. Proctor (ed.), Science, Religion, and the Human Experience, New York and Oxford: Oxford University Press, 237-60.

Cattell, J. M. (1904). 'The Conceptions and Methods of Psychology', Popular Science Monthly, 60: oo-oo.

Clark, A. (2001). Mindware: An Introduction to the Philosophy of Cognitive Science. New York and Oxford: Oxford University Press.

Cosmelli, D., David, O., Lachaux, J.-P., Martinerie, J., Garnero, L., Renault, B., and Varela, F. J. (2004). 'Waves of Consciousness: Ongoing Cortical Patterns during Binocular Rivalry', Neuroimage, 23: 128-40.

Depraz, N, Varela, F. J., and Vermersch, P. (2003). On Becoming Aware: A Pragmatics of Experiencing. Amsterdam and Philadelphia: John Benjamins Press.

Dreyfus, G. (1997). Recognizing Reality: Dharmakirti's Philosophy and its Tibetan Interpretations. Albany, NY: State University of New York Press.

- and Thompson, E. (2007). 'Indian Theories of Mind', in P. D. Zelazo, M. Moscovitch, and E. Thompson (eds.), The Cambridge Handbook of Consciousness, New York and Cambridge: Cambridge University Press.

Freeman, W. J. (1999). How Brains Make up their Minds. London: Weidenfeld \& Nicolson.

Frith, C. (2002). 'How Can We Share Experiences?', Trends in Cognitive Sciences, 6: 374.

Gould, S. J. (1999). Rocks of Ages: Science and Religion in the Fullness of Life. New York: Ballantine.

Hurlbert, R. T., and Heavey, C. L. (2001). 'Telling What We Know: Describing Inner Experience', Trends in Cognitive Sciences, 9: 400-3.

Hut, P. (2003). 'Conclusion: Life as a Laboratory', in B. Alan Wallace (ed.), Buddhism and Science: Breaking New Ground, New York: Columbia University Press, 399-416.

Jack, A. I., and Roepstorff, A. (2002). 'Introspection and Cognitive Brain Mapping: From Stimulus-Response to Script-Report', Trends in Cognitive Sciences, 6: 333-9.

_ _ (2003) (eds.). Trusting the Subject? The Use of Introspective Evidence in Cognitive Science, i. Thorverton, UK: Imprint Academic.

James, W. (1981). The Principles of Psychology. Cambridge, Mass.: Harvard University Press.

- (1997). The Varieties of Religious Experience. New York: Touchstone Press.

KöHler, W. (1947). Gestalt Psychology. New York: Liveright.

Le Van Quyen, M., and Petitmengin, C. (2002). 'Neuronal Dynamics and Conscious Experience: An Example of Reciprocal Causation before Epileptic Seizures', Phenomenology and the Cognitive Sciences, 1: 169-80.

Lutz, A., and Thompson, E. (2003). 'Neurophenomenology: Integrating Subjective Experience and Brain Dynamics in the Neuroscience of Consciousness', Journal of Consciousness Studies, 10: 31-52.

Dunne, J., and Davidson, R. J. (2007). 'Meditation and the Neuroscience of Consciousness: An Introduction', in P. D. Zelazo, M. Moscovitch, and E. Thompson (eds.), The Cambridge Handbook of Consciousness, New York and Cambridge: Cambridge University Press. 
Lachaux, J.-P., Martinerie, J., and Varela, F. J. (2002). 'Guiding the Study of Brain Dynamics by Using First-Person Data: Synchrony Patterns Correlate with Ongoing Conscious States during a Simple Visual Task', Proceedings of the National Academy of Sciences (USA), 99: 1586-91.

- Greischar, L. L., Rawlings, N. B., Ricard, M., and Davidson, R. J. (2004). 'LongTerm Meditators Self-Induce High-Amplitude Gamma Synchrony during Mental Practice', Proceedings of the National Academy of Sciences (USA), 101: 16369-73.

Lyons, W. (1986). The Disappearance of Introspection. Cambridge, Mass.: MIT Press.

McGee, M. (2000). Transformations of Mind: Philosophy as Spiritual Practice. Cambridge: Cambridge University Press.

Merleau-Ponty, M. (1962). Phenomenology of Perception, trans. Colin Smith. London: Routledge.

Moran, D. (2000). Introduction to Phenomenology. London: Routledge.

Newberg, A., D'Aquili, E., and Rause V. (2001). Why God Won't Go Away: Brain Science and the Biology of Belief. New York: Ballantine Books.

Nisbett, R. E., and Wilson, T. D. (1977). 'Telling More Than We Can Know: Verbal Reports on Mental Processes', Psychological Review, 84: 231-59.

Price, D., Barrell, J., and Rainville, P. (2002). 'Integrating Experiential-Phenomenological Methods and Neuroscience to Study Neural Mechanisms of Pain and Consciousness', Consciousness and Cognition, 11: 593-608.

Rainville, P. (2005). 'Neurophénoménologie des états et des contenus de conscience dans l'hypnose et l'analgésie hypnotique', Théologique, 12: 15-38.

Taylor, E. (1996). William James, on Consciousness beyond the Margin. Princeton: Princeton University Press.

Thompson, E. (2005). 'Empathy and Human Experience', in J. Proctor (ed.), Science, Religion, and the Human Experience, New York and Oxford: Oxford University Press, 261-86.

(2006). Mind in Life: Biology, Phenomenology, and the Sciences of Mind. Cambridge, Mass.: Harvard University Press.

and Varela, F. J. (2001). 'Radical Embodiment: Neural Dynamics and Consciousness', Trends in Cognitive Sciences, 5: 418-25.

Varela, F. J. (1996). 'Neurophenomenology: A Methodological Remedy for the Hard Problem', Journal of Consciousness Studies, 3: 330-50.

— and Shear, J. (1999) (eds.). The View from Within: First-Person Approaches to the Study of Consciousness. Thorverton, UK: Imprint Academic.

— Thompson, E., and Rosch, E. (1991). The Embodied Mind: Cognitive Science and Human Experience. Cambridge, Mass.: MIT Press.

Wallace, B. A. (1998). The Bridge of Quiescence: Experiencing Tibetan Buddhist Meditation. La Salle, Ill.: Open Court.

- (1999). 'The Buddhist Tradition of shamatha: Methods for Refining and Examining Consciousness', in Varela and Shear (1999), 175-88.

- (2000). The Taboo of Subjectivity: Toward a New Science of Consciousness. New York: Oxford University Press.

_ (2003a) (ed.). Buddhism and Science: Breaking New Ground. New York: Columbia University Press.

- (2003b). 'Introduction: Buddhism and Science', in Wallace (2003), 1-29.

- (2005). 'The Intersubjective Worlds of Science and Religion', in J. Proctor (ed.), Science, Religion, and the Human Experience, New York and Oxford: Oxford University Press, $309-27$. 